\title{
MUdANÇAS NAS CONCEPÇÕES DO PROFESSOR DO ENSINO FUNDAMENTAL EM RELAÇÃO À INCLUSÃO APÓS A ENTRADA DE ALUNOS COM DEFICIÊNCIA EM SUA CLASSE
}

\author{
CHANGES IN ELEMENTARY SCHOOL TEACHERS' CONCEPTIONS REGARDING \\ INCLUSION AFTER THE ADMISSION OF DISABLED STUDENTSIN THEIR CLASSROOM S
}

\author{
Ana Paula Húngaro MONTEIRO ${ }^{1}$ \\ EduardoJoséMANZINI²
}

\begin{abstract}
RESU M O: as concepçães dos professores podem determinar as atitudes sociais em relação à inclusão do aluno com deficiência na sala de aula. Dentre dessa temática, pode-se questionar: a concepção deinclusão do professor do ensino regular muda no decorrer do ano letivo após a entrada de alunos com deficiência? Assim, objetivouse identificar a existência de mudanças de concepções do professor do ensino regular em relação à inclusão. Participaram do estudo cinco professores do ensino regular que atuavam em sala de aula com pelo menos um aluno com deficiência, em três escolas de Município do interior Paulista. Os dados foram coletados durante um ano letivo por meio de três procedimentos: entrevista não-estruturada; segmento bimestral das informações por meio de cadernos de conteúdo e entrevista semi-estruturada, ao final do ano. Os dados foram tratados por meio da técnica designada como análise da enunciação. Dessa análise, foram estabelecidas classes e subclasses, aferidas por juízes para verificar o grau de concordância da análise. Os resultados mostraram mudanças de concepções nas subclasses: expectativa em relação à inclusão do aluno com deficiência no ensino regular, experiência em relação à inclusão, perfil do aluno para ser matriculado no ensino regular; ritmo de aprendizagem do aluno com deficiência na sala de aula regular, avaliação da aprendizagem do aluno com deficiência, dificuldades em lidar com a diversidade, dificuldade em lidar com a disciplina/ comportamento do al uno com deficiência e dificuldade para ensinar o aluno com deficiência. Conclui-se que a entrada, por si só, do aluno com deficiência no ensino regular não garantiu a mudança de concepção dos professores.
\end{abstract}

PALAVRAS-CHAVE: concepção; inclusão educacional; educação especial.

A BSTRACT: teachers' conceptions can determinesocial attitudes in relation to theinclusion of disabled students in the classroom. Within this theme, one might ask: Do regular school teachers' conceptions of inclusion change during the school term after the admission of disabled students in the classroom? Thus, this study aimed to identify the existence of changes in regular education teachers' conceptions in relation to inclusion. Five regular school teachers who had at least one disabled student in the classroom, in three schools in the interior of the state of São Paulo, participated in the study. The data were collected throughout one school year using three procedures: non-structured interviews; follow-up information collected every two months in a content notebook and semi-structured interviews, at theend of theyear. The data weretreated by theenunciation analysis technique. From this analysis, classes and subclasses were established and evaluated by judges to verify the analysis' conformity. The results showed changes in conceptions in the subclasses: expectation regarding the disabled student's inclusion in regular school, experience regarding inclusion, student's profile to be registered in the regular school; learning pace of the disabled student in the regular classroom, learning assessment of the disabled student, difficulties in dealing with diversity, difficulty in dealing with discipline/ behavior of the disabled student and difficulty in teaching the disabled student. It was concluded that the admission of disabled students in the regular school in itself did not guarantee changes in the teachers' conceptions.

KEYWORDS: conception; educational inclusion; special education.

\footnotetext{
1 Mestre em Educação pelo Programa de Pós-graduação em Educação a Unesp, Marília. Professora Especializada aphmonteiro@bol.com.br

2 Doutor em Piscologia pela USP - SP. Docente do Programa de Pós-graduação em Educação e do Departamento de Educação Especial da Unesp, Marília - manzini@marilia.unesp.br
} 


\section{INTRODUÇão}

As ações, as soluções apresentadas para problemas diários, as iniciativas, as inovações que se buscam realizar, na vida pessoal e profissional, estão sempre embasadas em concepções que se tem sobre determinado assunto. Essas concepções são frutos de uma história, de uma herança cultural e são desenvolvidas dentro de um processo histórico, no qual estão incluídas as crenças e valores de cada indivíduo.

Mendes (1995) definiu o termo concepção como o resultado do conjunto deinformações que habilitam indivíduos, grupos sociais, a sociedade, ou a cultura, a: descrever as características do fenômeno, ou a forma como ele se manifesta; identificar o fenômeno com basenas características descritas; explicar sua ocorrência através do estabel ecimento de relações entre eventos determinados econseqüentes; derivar estratégias para intervir na condição. "As concepções envolveriam, portanto, um repertório ou conjunto de conhecimentos adquiridos no decorrer da história de vida das pessoas". (MENDES, 1995, p. 6)

Segundo Mendes (2001), a análise histórica da evolução do conceito de deficiência permite visualizar a relatividade de uma determinada concepção que parece sempre estar vinculada a um contexto histórico específico. Dessa forma, as concepções e o conhecimento atual não devem ser encarados como dogmas ou verdades absolutas, mas sim como verdades rel ativas (grifos do autor). O que parece certo, hoje, poderá ser considerado tremendamenteincorreto amanhã, portanto, é importante agir com cautela e abdicar dos radical ismos.

A partir das experiências vividas, das informações recebidas, compartilhadas com os grupos sociais aos quais o indivíduo pertence, da cultura em que estão inseridos estes grupos, da linguagem utilizada, éque são construídos os conceitos, o que acontece de forma processual e dinâmica.

As ações de um indivíduo têm como base uma concepção que foi desenvolvida dentro de um processo histórico, sendo assim, pode-se dizer que o conceito que se tem de algo direciona a prática, ou ainda, determina as atitudes. Portanto, em se tratando da temática inclusão de alunos com deficiência em salas de aulas de ensino regular, as atitudes do professor em relação ao ensino desse aluno estariam diretamente ligadas ao seu conceito de inclusão.

Alguns pesquisadores na área da Educação Especial realizaram estudos relacionados à concepção de inclusão educacional, dentre eles: Janial e Manzini (1999); Vitaliano (2002); Silva e Pereira (2002), Tessaro (2005), Dal-forno e Oliveira (2005). De forma geral, a literatura apresenta um grande número de estudos sobre concepção de inclusão/ integração educacional , sobre percepções, opiniões e pontos de vista de professores da educação especial, da educação regular, de pais dealunos com deficiência ou não, dealunos com esem deficiência eprofissionais da educação em geral sobre o tema em questão. 
A nalisando esses estudos, pode-se verificar que os eles apontam para uma anál ise circunstancial, ou seja, os estudos mostram como que uma fotografia daquele espaço e tempo delimitados, no qual a pesquisa transcorreu.

Os estudos encontrados que tratam de mudanças de concepções em relação à inclusão (GAMBA RO, 2002; PEREIRA, 2002; ORTIZ, 2003; ROSA, 2003) se referem às mudanças de concepções observadas após a realização de trabal hos de intervenção com professores, incluindo cursos de capacitação para a inclusão, programas ereuniões para orientação, discussão eacompanhamento do professor. Assim, não se têm informações sobre o processo de mudança das concepções dos professores em relação à inclusão, caso ocorram, única e exclusivamente, após o ingresso de um aluno com deficiência na sala de aula regular.

Nesse sentido, a proposta do presente estudo visa responder às questões: a concepção de inclusão do professor do ensino regular muda no decorrer do ano letivo após a entrada de alunos com deficiência? Em qual direção essa concepção se modifica?

\section{Desenvolvimento do estudo}

Para a seleção dos participantes foram usados dois critérios: 1) estar atuando em sala de aula do ensino regular, fundamental, ciclo I, pela primeira vez com aluno com deficiência e2) dispor-sea participar da pesquisa, assi nando termo de consentimento esclarecido ${ }^{3}$.

Participaram da pesquisa cinco professores, sendo que quatro deles trabal havam em escolas estaduais e um trabal hava em escola municipal.

O Quadro 1 apresenta informações sobre os participantes da pesquisa.

\begin{tabular}{|c|c|c|c|c|c|c|}
\hline Participantes & Escola & Idade & $\begin{array}{l}\text { Série em que } \\
\text { trabalhava }\end{array}$ & $\begin{array}{l}\text { Número de alunos com } \\
\text { deficiência na sala }\end{array}$ & $\begin{array}{c}\text { Tipo de } \\
\text { escola }\end{array}$ & $\begin{array}{l}\text { Tempo de } \\
\text { magistério }\end{array}$ \\
\hline P1 & A & 47 & $1^{\text {a }}$. série & 2 & Estadual & 24 anos \\
\hline P2 & A & 54 & $4^{\text {a }}$. série & 1 & Estadual & 22 anos \\
\hline P3 & A & 49 & $4^{\text {a }}$. série & 1 & Estadual & 27 anos \\
\hline P4 & B & 36 & $3^{\text {a }}$. série & 1 & Estadual & 15 anos \\
\hline P5 & C & 24 & $3^{\text {a }}$. série & 1 & Municipal & 6 anos \\
\hline
\end{tabular}

Quadro 1 - Identificação dos participantes.

\footnotetext{
${ }^{3} \mathrm{O}$ projeto de pesquisa foi aprovado pelo comitê de ética da Faculdade de Filosofia e Ciências, Unesp, Marília, processo no 2549/ 2005.
} 
O Quadro 2 traz informações sobre a formação dos participantes.

\begin{tabular}{|l|l|l|l|}
\hline Partic. & Formação & Conclusão & Cursos complementares recentes \\
\hline P1 & Estudos Sociais & 1979 & Alfabetização (2004), Racismo (em andamento) \\
\hline P2 & Magistério & - & Racismo (em andamento) \\
\hline P3 & $\begin{array}{l}\text { Educação Física, } \\
\text { Pedagogia }\end{array}$ & 1976,1978 & Alfabetização (em andamento) \\
\hline P4 & Geografia & 1990 & $\begin{array}{l}\text { Alfabetização (2004), Complementação Pedagógica } \\
\text { (em andamento) }\end{array}$ \\
\hline P5 & Pedagogia & 2001 & $\begin{array}{l}\text { Pós-graduação Lato sensu em piscopedagogia (2003), } \\
\text { LIBRAS (2004), Hab. em deficiência auditiva (2005) }\end{array}$ \\
\hline
\end{tabular}

Quadro 2 - Formação dos participantes da pesquisa.

A pesar de os alunos atendidos pelos professores não serem os participantes da pesquisa, foi feito um levantamento de informações sobre esses alunos no sentido de auxiliar a discussão sobre os dados.

\begin{tabular}{|c|c|c|c|}
\hline Alunos & $\begin{array}{c}\text { Idade } \\
\text { (em anos) }\end{array}$ & Sexo & Diagnóstico/Comprometimento \\
\hline Alunos de P1: & 10 & $\mathrm{M}$ & $\begin{array}{l}\text { A1- Resultados abaixo da média a nível mental, perceptivo motor } \\
\text { e desempenho escolar; comprometimento a nível emocional; } \\
\text { orientação para freqüentar classe especial (diagnóstico da } \\
\text { psicóloga - prontuário da escola). }\end{array}$ \\
\hline & 10 & M & $\begin{array}{l}\text { A2- Atraso de desenvolvimento neuropsicomotor, distúrbio de } \\
\text { aprendizagem (diagnóstico da psicóloga); hiperativo (diagnóstico } \\
\text { da Terapeuta Ocupacional - prontuário da APAE). }\end{array}$ \\
\hline $\begin{array}{c}\text { Aluno de P2 e P3 } \\
\left.\text { ( } 4^{\text {a }} \text { série }\right)\end{array}$ & 13 & $\mathrm{~F}$ & $\begin{array}{l}\text { Atraso no desenvolvimento global, não tem deficiência mental, } \\
\text { capacidade intelectual abaixo da média esperada, orientação para } \\
\text { freqüentar classe especial e posteriormente ser inserida no ensino } \\
\text { comum (diagnóstico da psicóloga - prontuário da escola) }\end{array}$ \\
\hline $\begin{array}{l}\text { Aluno de } \mathrm{P} 4 \\
\text { (3 } 3^{\mathrm{a}} \text { série) }\end{array}$ & 11 & $\mathrm{M}$ & $\begin{array}{l}\text { Deficiência Auditiva (prontuário da escola), não há indicações } \\
\text { sobre o grau da perda, segundo a professora especializada é } \\
\text { moderada. }\end{array}$ \\
\hline $\begin{array}{c}\text { Aluno de P5 } \\
\left(3^{\mathrm{a}} \text { série }\right)\end{array}$ & 12 & $\mathrm{M}$ & Deficiência mental leve (prontuário da escola). \\
\hline
\end{tabular}

Quadro 3 - Identificação dos alunos inseridos na sala de aula regular dos participantes da pesquisa.

\subsection{OLETA DE DADOS}

Os procedimentos e instrumentos utilizados para a coleta de dados foram: entrevista não-estruturada, caderno de conteúdo e entrevista semiestruturada.

A coleta foi realizada em seis etapas e durou todo o ano letivo escolar. Na primeira etapa, realizada antes do primeiro contato do professor com o aluno 
com deficiência, foi utilizada a entrevista não-estruturada. Na segunda etapa realizada duas semanas após o início das aulas- na terceira, quarta equinta etapas - realizadas ao final de cada bimestre letivo - os dados foram col etados utilizando o caderno de conteúdos. Na sexta etapa - realizada ao final do quarto bimestre letivo - os dados foram coletados por meio de entrevistas semi-estruturadas.

A entrevista tem sido um dos meios mais adequados para obter certos tipos de informações, tais como as que dizem respeito a con cepções que setem sobre determinado objeto (DIAS; OMOTE, 1995). N esse sentido, seria, então, um procedimento adequado por meio do qual o objetivo da presentepesquisa pudesse ser atingido.

A o utilizar a entrevista não-estruturada (MANZINI, 1991; QUEIROZ, 1991), o entrevistador não tem a necessidade de estar pontuando as questões. A dinâmica é permitir que a informação corra fluentemente, de acordo com o relato do entrevistado, sem correr o risco de limitar a fala do entrevistado, sem criar amarras ou entraves para a pesquisa, "mas para abrir perspectivas para análise e interpretação de idéias". (MANZINI, 2004, p. 3).

A realização da entrevista não-estruturada teve como objetivo verificar a concepção inicial do professor do ensino regular em relação à inclusão; para tal, foi elaborada uma única questão: "V ocê vai receber na sua sala de aula um aluno com deficiência, o que você está achando disso?". A própria fala do entrevistado é que foi conduzindo edirecionando a entrevista. A s entrevistas iniciais duraram de 15 a 20 minutos.

Os participantes foram informados ao final da entrevista de que as informações gravadas seriam transcritas eorganizadas em forma de caderno equeo pesquisador voltaria a procurá-los após duas semanas do início das aulas para agendar um novo encontro e realizar a segunda etapa da coleta de dados.

O caderno de conteúdo é um procedimento utilizado para coletar dados de natureza verbal. Foi desenvolvido por Bori et al em 1977 (TUNES; SIMÃO, 1998) e empregado por vários pesquisadores brasileiros.

O caderno de conteúdo tem os seguintes objetivos: 1) possibilitar ao pesquisador a reprogramação da coleta de dados; 2) validar o relato pelo próprio entrevistado; 3) permitir a reformulação dos conteúdos transcritos; 4) enriquecer as informações fornecidas anteriormente. O uso do caderno de conteúdo permite, ainda, a ampliação efidedignidade das informações obtidas (TUNES; SI MÃ O, 1998; FUJISAWA; 2000).

No presente estudo, os relatos transcritos foram dispostos no caderno de conteúdo em forma de colunas. Foi organizado um caderno para cada um dos participantes, portanto, cinco cadernos. Em virtude de a primeira coleta ter sido real izada por meio deentrevista não-estruturada, al guns temas dos relatos diferiram ao comparar os relatos entre os participantes. Conseqüentemente, a organização dos cadernos, no que se refere à formatação dos temas das colunas, diferiu. Porém, 
para construção de cada caderno usou-se o mesmo critério: as colunas foram organizadas, da esquerda para a direita, de acordo com a ordem de importância para o objetivo da pesquisa.

No momento da segunda coleta, foi entregueao participanteo caderno de conteúdo, o pesquisador também possuía um caderno igual ao do participante, contendo todo o relato transcrito, organizado em forma decolunas. A sinformações foram lidas e os relatos gravados. A o final da leitura do caderno de conteúdo, era perguntado ao participante se gostaria de acrescentar alguma informação, caso contrário era encerrada a gravação e a coleta.

Foi informado aos participantes que os relatos coletados nesta segunda etapa seriam transcritos e inseridos naquele mesmo caderno e que no próximo encontro os participantes teriam, novamente em mãos, todas as informações anteriores fornecidas. Isso ocorreu durantetoda a fase de coleta de dados por meio do caderno de conteúdo.

Esse procedimento, para saber se as concepções sobre inclusão modificar-se-iam, foi profícuo e permitiu buscar informações após certos períodos de contato entre professor da classe comum ealuno com deficiência.

Salienta-se que procedimento semel hante foi utilizado por Manzini e Simão (1993), que obtiveram resultados sobrea mudança deconcepções em alunos universitários.

A sexta etapa decoleta de dados foi real izada ao final do quarto bimestre letivo, por meio de entrevista semi-estruturada, para tal foi elaborado previamente um roteiro.

Cada questão do rotei ro apresentava resumidamentetrechos derelatos das participantes referentes a assuntos específicos abordados em cada etapa de coleta. Para exemplificar o rotei ro, segue uma das questões do rotei ro para P1: N 0 começo ( 1 a etapa) você falou que tinha medo em lidar com o emocional do aluno com deficiência, logo após ( 2 a e $3^{a}$ etapa) você disse que ainda estava insegura e em seguida (4a e 5ạ etapa) você relatou que não tinha mais medo, para fecharmos esta questão o que você poderia dizer sobre isso?

Devido à natureza dos dados, foi necessário elaborar um roteiro diferente para cada participante. Nesta fase de coleta, a duração das entrevistas variou de 30 a 56 minutos.

\subsection{TRANSCRIÇÃO INFORMAÇõES}

As informações verbais coletadas por meio dos três procedimentos foram transcritas na íntegra eadotaram-se os seguintes critérios para a transcrição: 1) as pausas curtas foram indicadas por vírgula; 2 ) as pausas longas com reticências; 3) sinais de pontuação para entoações: ponto deexclamação, de interrogação, ponto final, dois pontos; 4) letras em caixa alta para indicar ênfase em determinadas 
sílabas ou palavras; 5) aspas simples em relatos de relatos, como por exemplo: [...] porque o al uno falou para mim: 'No ano que vem vocêvai ser minha professora'; 6) supressões de falas foram indicadas com colchetes e reticências [...]; 7) interpolações, acréscimos ou comentários indicados apenas com colchetes [...].

\subsection{Análise e o tratamento das Informações}

O tratamento das informações foi inspirado na análise de conteúdo (BARDIN , 2000) e, teoricamente, apoiado pela técnica designada como análise da enunciação.

Para Bardin (2000), a análise da enunciação possui duas características que a diferencia das demais técnicas: 1) apóia-se numa concepção da comunicação como processo enão como dado; 2) desvia-se das estruturas edos elementos formais.

Os elementos formais eas estruturas seriam definidos como el ementos gramaticais esintáticos, que seriam utilizados para apreender os significados, mas que, por si só, não seriam objetos de análise.

Bardin (2000) considerou que a entrevista não-diretiva (neste trabalho, designada entrevista não-estruturada) seria um material "privilegiado" da análise da enunciação.

Parece, pois que essa técnica, assim designada por Bardin (2000), seria útil para analisar os dados, pois o objetivo do trabalho seria verificar sehaveria ou não mudanças de concepções de professores do ensino regular ao receber, em sua sala, al unos com deficiência ese haveria uma tendência demudança nas concepções, ou seja, teoricamente verificar um processo.

$\mathrm{Na}$ análise da enunciação, é possível analisar tanto a informação lingüística como paral inguística (anotações desilêncio, onomatopéias, perturbações de palavras e aspectos emocionais como riso, ironia). Sal ienta-se que, nos dados coletados na presente pesquisa, não foi realizada a anál ise paral inguística por fugir aos objetivos da pesquisa.

$\mathrm{N}$ a análise da enunciação, busca-se uma coerência interna dos dados e para isso énecessária uma análise temática anterior. A análisetemática étransversal, recorta o conjunto de entrevistas através de um quadro de categorias projetadas sobre os conteúdos. Essas categorias são construídas a partir de proposições (frases, palavras, parágrafos) que são agrupadas de acordo com o grau de semel hança. Essas categorias são codificadas por um nome, ou seja, classificadas por um título. A partir dessas categorias incide-se a análise lógica.

$\mathrm{Na}$ análise lógica (BARDIN, 2000), verificam-se as relações entre as proposições, ou seja, são real izadas comparações.

A poiando-se nesses aportes teóricos, desenvolveu-se a análise e tratamento dos dados. 
Primeiramente, as informações transcritas advindas dos três procedimentos decoleta utilizad os foram repetidamentelidas como sugere Bardin (2000), ou seja, foi realizada uma leitura flutuante na qual o texto foi conhecido e as primeiras impressões e orientações foram se tornando mais precisas em função dos objetivos da pesquisa.

Posteriormente, baseados nas proposições (palavras, frases, parágrafos) foi feito o agrupamento por semelhança. A cada agrupamento, designou-se um título, ou seja, cada agrupamento foi classificado por um nome.

A pós essa análise, foram identificadas seis classes temáticas. Essas classes foram identificadas em cada uma das sessões de coletas e para cada um dos entrevistados. As proposições foram, então, apresentadas em quadros, seqüencialmente para cada sessão, dentro das classes temáticas identificadas. 0 material coletado foi utilizado em sua totalidade, foram construídas classes que abrangessem todas as informações coletadas, desta forma nenhum dado foi desprezado. O exemplo a seguir ilustra a composição dos quadros.

\begin{tabular}{|c|c|c|c|c|}
\hline $1^{\mathrm{a}}$. sessão de coleta & $2^{\mathrm{a}}$. sessão de coleta & $3^{\mathrm{a}}$. sessão de coleta & $4^{\mathrm{a}}$. sessão de coleta & $5^{\mathrm{a}}$. sessão de coleta \\
\hline $\begin{array}{l}\text { "[...] O meu medo } \\
\text { maior é o emocional, se } \\
\text { for uma criança } \\
\text { deficom } \\
\text { desconcientrolada } \\
\text { emocional". (P1) }\end{array}$ & $\begin{array}{l}\text { "Você ainda sente esse } \\
\text { medo em relação às } \\
\text { reações dessas crianças } \\
\text { [alunos com } \\
\text { deficiência]? Não, não } \\
\text { tenho esse medo agora, } \\
\text { porque eu já percebi } \\
\text { que não são agressivos } \\
\text { [os alunos com } \\
\text { deficiência] [...]". (P1) }\end{array}$ & $\begin{array}{l}\text { "Eu continuo ainda } \\
\text { tendo aquele cuidado } \\
{[\ldots] \text { quando eu vou me }} \\
\text { relacionar com eles [os } \\
\text { alunos rom } \\
\text { deficiência]... quando } \\
\text { eu vou corrigir eles...". } \\
(\mathrm{P} 1)\end{array}$ & $\begin{array}{l}\text { "Não, já perdi aquele } \\
\text { medo, já trabalho com } \\
\text { eles [alunos com } \\
\text { deficiência] } \\
\text { normalmente". (P1) }\end{array}$ & $\begin{array}{l}\text { "Não é medo, eu não } \\
\text { tenho medo, sabe, o } \\
\text { único problema que eu } \\
\text { sinto, eu fico ansiosa, } \\
\text { porque eu acho que eu } \\
\text { tinha que dar mais de } \\
\text { mim para eles, não dá } \\
{[\ldots] \text { ". (P1) }}\end{array}$ \\
\hline
\end{tabular}

Quadro 4 - Exemplo de uma classificação sobre o relato referente à subclasse Expectativa do professor em relação à inclusão do aluno com deficiência na sala deaula regular.

A pós a composi ção de todos os quadros, foi sel ecionada uma amostra a ser enviada a juízes para validar a classificação temática. Para essa amostra, foram selecionados sete quadros, sendo que dois deles apresentavam um grau elevado de dificuldade para agrupar as falas, dois que apresentavam um grau médio de dificuldade e três deles de fácil classificação dos conteúdos temáticos. Esses sete quadros foram enviados a dois juízes, doutorandos do Programa dePós-graduação em Educação da Unesp, Marília, e que tinham larga experiência com o uso de entrevistas e com o tema em questão.

O grau de concordância foi aferido a partir da fórmula: Índice de concordância é igual ao número de concordâncias dividido pela soma das concordâncias e discordâncias, multiplicado por 100 (FAGUNDES, 1999). A tabela a seguir apresenta os índices de concordância mensurados. 
Tabela 1 - índice de concordância mensurado.

\begin{tabular}{llll}
\hline $\begin{array}{l}\text { Grau de dificuldade de } \\
\text { classificação }\end{array}$ & $\begin{array}{l}\text { Concordância entre juiz } \\
\text { A e o pesquisador }\end{array}$ & $\begin{array}{l}\text { Concordância entre juiz } \\
\text { B e o pesquisador }\end{array}$ & $\begin{array}{l}\text { Concordância entre juiz } \\
\text { A e juiz B }\end{array}$ \\
\hline Difícil & $80 \%$ & $40 \%$ & $50 \%$ \\
Média & $100 \%$ & $45,4 \%$ & $70 \%$ \\
Fácil & $93,3 \%$ & $80 \%$ & $80 \%$ \\
\hline
\end{tabular}

Podemos verificar que quanto menor o nível de dificuldade maior a concordância entre os juízes. Ao fazer a somatória geral dos três níveis de dificuldade, encontram-se os seguintes índices de concordância: com juiz A, 97\%, com o juiz B, 58\%, e entre o juiz A eB, 71\%. Segundo Bauer eGaskell (2004), podeseconsiderar a fidedignidade como sendo muito alta quando $r>0.90$, al ta, quando $r>0.80$, e aceitável, na amplitude entre $0.66<r>0.79$.

Verificando o porquê do baixo índice de concordância com o Juiz B, pôde-seobservar queal guns nomes declasses estavam inadequados. A o incorporar tais sugestões, o índice geral de concordância foi o de 72\%. Dessa forma, foram incorporadas as sugestões apresentadas por ambos os juízes.

A partir das disposições dos exemplares de falas (proposições) categorizados em cada quadro, verificaram-se as relações entre as proposições. Assim, foram feitas comparações entre cada uma das sessões de coleta para identificar se as concepções dos participantes haviam se modificado, ou seja, foi realizada a análise lógica (BARDIN , 2000).

A partir dessa análise, foram construídos novos quadros para mapear as classes temáticas e verificar a ocorrência ou não de mudanças de concepções dos participantes.

\section{Resultados e discussão}

Para apresentação dos resultados do presente trabal ho, optou-se por um recorte das concepções que indicaram modificações durantea pesquisa original (MONTEIRO, 2006). Dessa forma, será apresentada uma parte das categorias analisadas em cinco das seis sessões de coleta e, posteriormente, um resumo geral das mudanças de concepções.

\subsection{EDO DO PROFESSOR FRENTE A ENTRADA DO ALUNO COM DEFICIÊNCIA NA SUA SALA DE AULA}

Os participantes, em seus relatos, indicaram, inicialmente, sentimentos demedo em relação ao comportamento do al uno com deficiência eem não conseguir ensiná-lo. Com o decorrer do tempo e experiência junto aos alunos, foi possível perceber que as concepções (P1, P3 e P4) se modificaram. O Quadro que segue ilustra os sentimentos de dois dos participantes. 


\begin{tabular}{|c|c|}
\hline Sessão & Relatos \\
\hline 1 & $\begin{array}{l}\text { "[...] O meu medo maior é o emocional, se for uma criança [com deficiência] descontrolada } \\
\text { no emocional". (P1) } \\
\text { "[...] eu não sei em que nível ele está, qual a dificuldade dele". (P1) } \\
\text { "O que me preocupa mais é se eu vou dar conta da parte pedagógica com esses alunos [...] } \\
\text { eu não sei como eles vão chegar [...] eu nem conheço as crianças, vou conhecer segunda- } \\
\text { feira [...] é uma expectativa [...] se eu conseguir fazer com que eles [alunos com } \\
\text { deficiência] aprendam e acrescentar alguma coisa [...] eu já vou ficar feliz". (P3) }\end{array}$ \\
\hline 2 & $\begin{array}{l}\text { Você ainda sente esse medo em relação às reações desses alunos? Não, não tenho esse } \\
\text { medo agora, porque eu já percebi que não são agressivos [os alunos com deficiência] [...]". } \\
\text { (P1) } \\
\text { "[...] eu achava que eu ia ter que dar aquela maior atenção [para o aluno com deficiência], } \\
\text { mas foi uma atenção normal". (P1) }\end{array}$ \\
\hline 3 & $\begin{array}{l}\text { "Eu continuo ainda tendo aquele cuidado }[\ldots] \text { quando eu vou me relacionar com eles }[\text { os } \\
\text { alunos com deficiência]... quando eu vou corrigir eles...". (P1) } \\
\text { "[...] aquela expectativa de MEdo que eu estava [...] eu estava ansiosa e com medo porque } \\
\text { eu não conhecia }[\ldots . .] \text { estou MAIS tranqüila }[\ldots] \text { aquela expectativa minha, foi tudo menos } \\
{[\ldots] " .(\mathrm{P} 3)}\end{array}$ \\
\hline 4 & $\begin{array}{l}\text { "Não, já perdi aquele medo, já trabalho com eles [alunos com deficiência] normalmente". } \\
\text { (P1) } \\
\text { "Está sendo difícil lidar com o emocional destes alunos [com deficiências]? Não, por } \\
\text { enquanto não estou tendo dificuldade". (P1) } \\
\text { "Como está agora a sua expectativa em relação à aluna? Agora eu estou tranqüila [...] eu } \\
\text { acho que a 4a. série ela [a aluna com deficiência] vai fazer bem". (P3) }\end{array}$ \\
\hline 5 & $\begin{array}{l}\text { "Não é medo, eu não tenho medo, sabe, o único problema que eu sinto, eu fico ansiosa, } \\
\text { porque eu acho que eu tinha que dar mais de mim para eles, não dá [...]". (P1) } \\
\text { "Você está tendo dificuldade para lidar com o emocional do aluno? Não, porque eles não } \\
\text { estão dando trabalho nesse ponto. Não encontrei ainda dificuldade grande".(P1) } \\
\text { "Eu tinha muito medo... foi melhor do que eu esperava, no começo eu estava muito } \\
\text { medrosa, muito insegura, medo do comportamento da sala [...] eu achei que fosse ter muito } \\
\text { mais problemas, eu não tive problemas com ela [aluna com deficiência] [...]". (P3) } \\
\text { "Com essa prova do } 3^{\circ} \text { bimestre que eu percebi mais dificuldade, ela precisa de mais tempo } \\
\text { para resolver, para pensar, raciocinar, eu fico um pouco preocupada com o desempenho } \\
\text { dela depois sim, vamos ver o } 4^{\circ} \text { bimestre como é que ela se sai, eu fico preocupada". (P3) }\end{array}$ \\
\hline
\end{tabular}

\section{Quadro 5 - Medo professor frente ao aluno com deficiência.}

De acordo com Melo e Martins (2004) é natural que sentimentos de medo, insegurança, pena, entre outros, sejam manifestados, inicialmente, pelos integrantes da escola regular diante da inclusão do aluno com deficiência, uma vez que, de uma maneira geral, existe desconhecimento e também idéias preconcebidas em relação à deficiência e as pessoas que a apresentam.

P2 relatou o medo em relação à diferença de idade acentuada entre o grupo e o aluno com deficiência. Conforme estabelecem documentos como o Referencial Curricular N acional para a Educação Infantil (BRASIL, 1998) a idade cronológica do aluno com deficiência deve ser considerada.

\section{A participanterelatou também expectativas em relação a como ensinar o aluno com deficiência.}




\subsection{EXPECTATIVA DO PROFESSOR FRENTE AO ALUNO COM DEFICIÊNCIA}

\section{O quadro seguinte apresenta relatos sobre a expectativa dos participantes. Pôde-se perceber que parte dos participantes ficou sabendo da presença do aluno com deficiência em sua sala de aula por meio do pesquisador, ou seja, não houve nenhuma preparação anterior pela escola.}

\begin{tabular}{|c|c|}
\hline Sessão & Relatos \\
\hline 1 & $\begin{array}{l}\text { "Olha, para mim é uma surpresa [...] eu não sabia, não me avisaram que eu teria aluno } \\
\text { incluído [...] você que me informou [...]". (P1) } \\
\text { "Eu acho que tem que ter um jeito especial, não sei, para mim vai ser uma coisa nova". (P1) } \\
\text { "[...] vai ser uma experiência nova". (P5) } \\
\text { "[...] vai ser mais uma etapa que a gente vai estar enfrentando para aprimorar o } \\
\text { conhecimento". (P5) }\end{array}$ \\
\hline 2 & $\begin{array}{l}\text { "Eu tinha um pouco de receio, mas eu estou conseguindo muito com eles [os alunos com } \\
\text { deficiência] [...]". (P1) } \\
\text { "Está sendo diferente, uma experiência nova [...]". (P5) }\end{array}$ \\
\hline 3 & 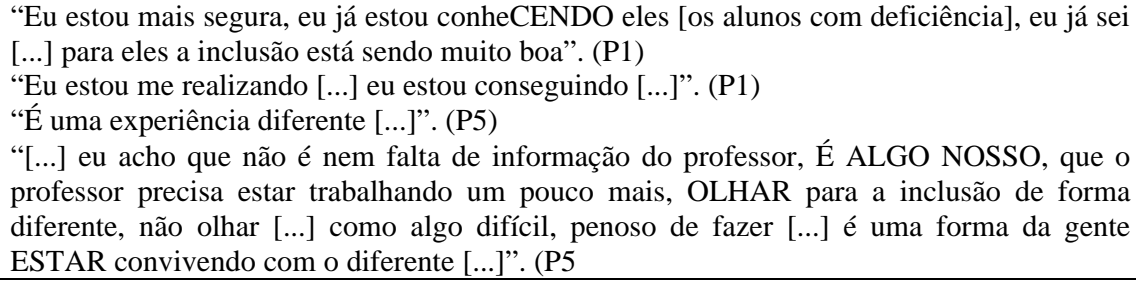 \\
\hline 4 & $\begin{array}{l}\text { "Eu gostei da experiência porque o jeito deles [dos alunos com deficiência] me cativou". } \\
\text { (P1) } \\
\text { "Como você avalia agora esta experiência de trabalhar com aluno com deficiência no } \\
\text { ensino comum? [...] ultimamente eu tenho entrado em contradição comigo mesma: ‘Estou } \\
\text { fazendo o que é necessário?' [...] estou em período de reflexão quanto à inclusão [...] [a } \\
\text { inclusão] tem contribuído muito porque as crianças agora vêem a necessidade do outro [...] } \\
\text { a aluna ficou preocupada: 'Como ele [aluno surdo de outra classe] vai escutar a música?' } \\
\text { [...]". (P5) } \\
\text { "Então, eles [alunos não com deficiências] cobram [atenção] [...] Já cobraram? No começo } \\
\text { do ano sim que foi fase de adaptação do aluno [com deficiência]". (P5) } \\
\text { "Você estava, então, dando mais atenção para ele [para o aluno com deficiência que aos } \\
\text { outros]? Isso, mas agora não, eu tento tratar todos iguais [...]". (P5) }\end{array}$ \\
\hline 5 & $\begin{array}{l}\text { "[...] não dá tempo para eu dar esta atenção especial para eles [...] não é uma criança que } \\
\text { você PAssa a atividade e deixa e ele faz perfeitamente, não faz, você tem que ficar ali, } \\
\text { falando". (P1) } \\
\text { "Dependendo da deficiência sim, eu estou de acordo com a inclusão, mas dependendo de } \\
\text { certas deficiência não [...] se tiver um aluno com deficiência física, que tem que ser levado } \\
\text { ao banheiro [...] vai ter que ter uma pessoa especial para levar". (P1) } \\
\text { "Já fala, ele é especial, ele precisa de uma atenção especial e o professor com } 35 \text { alunos } \\
\text { como ele vai dar atenção especial para esse aluno com deficiência?". (P1) } \\
\text { "Eu acho meio complicado ter } 31 \text { alunos em sala de aula e ter mais um com alguma } \\
\text { deficiência que você pode não dar conta de atender a necessidade daquele aluno, é } \\
\text { preocupante [...] eu me pergunto: 'Será que eu estou realmente atendendo a necessidade } \\
\text { desse aluno?' [...] Eu avalio como positivo, de crescimento profissional [...] foi uma } \\
\text { aprendizagem [...] tanto na vida profissional quanto pessoal porque vendo o avanço do } \\
\text { aluno você sente: 'Pelo menos estou contribuindo com alguma coisa'." (P5) }\end{array}$ \\
\hline
\end{tabular}

\section{Quadro 6 - Expectativa do professor frente ao aluno com deficiência.}


A maioria dos professores (P1, P2 eP3) ainda não havia sido informada de que teriam alunos com deficiência matriculados em suas salas de aula. Assim, os professores foram informados pela pesquisadora. Provavelmente, esse fato, juntamente com a falta de formação para atuar com tais al unos, tenha contribuído para que o desconforto para estes participantes fosse muito grande em relação à inclusão.

Segundo Saad (2003), a inclusão não se efetiva por imposi ção, mas por ações que possi bilitem sua viabilidade e pela disposição das pessoas em aceitar a diversidade como condição inerente à sociedade.

Janial e Manzini (1999) consideravam a integração da criança com deficiência no ensino regular como um desafio. Um dos participantes (P2), da mesma forma, verbalizou em seus relatos, inicialmente, que trabalhar com alunos com deficiência inseridos seria um desafio, com o decorrer do tempo e convivência com a aluna com deficiência, posteriormente, na terceira sessão de coleta a participante verbalizou: "[...] essa aluna NÃO me criou conflito... NEM é um desafio [...]”.

Em alguns relatos, como o de P5, pôde-se constatar que inicialmente mostrou-seaberto a novas experiência. N a sessão 5, épossível vislumbrar quecrítica ao sistema de ensino no que se refere ao elevado número dealunos em sala de aula.

\subsection{E XPECTATIVA do PROfESSOR FRENTE AO ALUNO COM DEFICIÊNCIA EM TERMOS ACADÊMICOS E CURRICULARES}

Um dos conceitos que apareceu na pesquisa se referiu à adaptação curricular. O relado de $\mathrm{P} 5$ ilustra esse tema.

\begin{tabular}{|c|c|}
\hline Sessão & Relatos \\
\hline 1 & $\begin{array}{l}\text { "[...] no currículo mesmo, vai ter que caminhar um pouco diferenciado [...] vai ter que } \\
\text { recorrer à adaptação sim [...] eu não conheço realmente o aluno [...]". (P5) }\end{array}$ \\
\hline 2 & $\begin{array}{l}\text { "[...] pegar o currículo da } 3^{\mathrm{a}} \text {. [série] e adaptar no nível dele [do aluno com deficiência] [...] } \\
\text { para facilitar o entendimento do aluno". (P5) }\end{array}$ \\
\hline 3 & $\begin{array}{l}\text { "[...] fazer umas adaptações, mas dentro do currículo da } 3^{\text {a }} \text {. série, eliminar alguns conteúdos, } \\
\text { objetivos secundários [...] ADAPTAÇÃO no currículo geral não [...] a gente não modificou } \\
\text { totalmente }[\ldots] " . \text { (P5) }\end{array}$ \\
\hline 4 & $\begin{array}{l}\text { "É, a gente faz uns arranjos dentro do próprio currículo [...] conteúdo mesmo é de } 2^{\text {a }} \text {. série a } \\
\text { matemática dele [aluno com deficiência] [...]". (P5) }\end{array}$ \\
\hline 5 & $\begin{array}{l}\text { Você ainda está trabalhando com o aluno com deficiência com currículo adaptado? Na } \\
\text { matemática ainda tem que fazer essa adaptação [...] o caderno dele é diferenciado [...]". (P5) }\end{array}$ \\
\hline
\end{tabular}

Quadro 7 - Concepção sobre adaptação curricular.

Os relatos indicam que a adaptação curricular se refere, em alguns momentos, a retirada deconteúdos. Em outros, se refere a adaptação de materiais, como por exemplo, a adaptação do caderno. 
Quando Valle e Guedes (2003) comentaram sobre as habilidades e competências para o profissional da educação frenteà inclusão, se referiram também à questão curricular. Segundo as autoras, o currículo deveria ser planejado e coordenado de maneira que assegurasse, a cada aluno, a aquisição dos conhecimentos e as habilidades essenciais respeitando a diversidade.

Segundo Blanco e Duk (1997), a existência de currículos abertos e flexíveis é uma condição fundamental para que se possa responder às diferentes necessidades dos alunos edos contextos sóci o-educacionais em que se desenvolve o processo de ensino-aprendizagem. A resposta às necessidades especiais dos alunos deve ser buscada no currículo comum, realizando-se ajustes e adaptações precisas, como via básica para que seja assegurada a igual dade de oportunidades. Deve ser proporcionado ao aluno um currículo equilibrado, que contemple suas necessidades individuais, sem perder de vista os objetivos que são perseguidos com os outros.

Em relação ao tema aprendizagem, com exceção de $\mathrm{P} 2$, todos os outros participantes (P1, P3, P4eP5) relataram queos al unos com deficiência apresentaram dificuldades na aprendizagem. Indicaram quais eram as dificuldades dos alunos, o que significa que os participantes identificaram quais eram as necessidades educacionais especiais de seus al unos. P5 verbalizou queo seu al uno com deficiência mental necessitaria de recurso diferenciado.

\begin{tabular}{|c|c|}
\hline Sessão & Relatos \\
\hline 1 & $\begin{array}{l}\text { "Eu sei que ele [aluno com deficiência] vai ter mais dificuldade que os outros [...] } \\
\text { Segundo a professora [do ano anterior] [...] tem dificuldade de leitura, de interpretação } \\
{[\ldots] \text { mas em matemática ele estava indo bem [...]". (P5 }}\end{array}$ \\
\hline 2 & $\begin{array}{l}\text { "A dificuldade que você achava que ele teria se confirmou? Confirmei }[\ldots] \text { em } \\
\text { matemática a gente viu que é o contrário, ele ainda está precisando do material concreto } \\
\text { [...] vai precisar usar recurso diferenciado }[\ldots] \text { às vezes ele só copia, não entende muito } \\
{[\ldots] \text { Na leitura ele tem uma defasagem muito grande }[\ldots] \text { produção de texto, ele até }} \\
\text { consegue, se ele tiver apoio }[\ldots] \text {.... (P5) }\end{array}$ \\
\hline 3 & $\begin{array}{l}\text { "[...] na matemática ele [aluno com deficiência] tem um atraso um pouquinho maior que } \\
\text { os outros alunos [...] tem que dar um material diferente". (P5) }\end{array}$ \\
\hline 4 & $\begin{array}{l}\text { "[...] a parte escrita ele [aluno com deficiência] continua tendo dificuldade [...] para } \\
\text { redigir texto, estruturar [...] ele tem uma grande defasagem em Matemática em relação } \\
\text { aos demais". (P5) }\end{array}$ \\
\hline 5 & 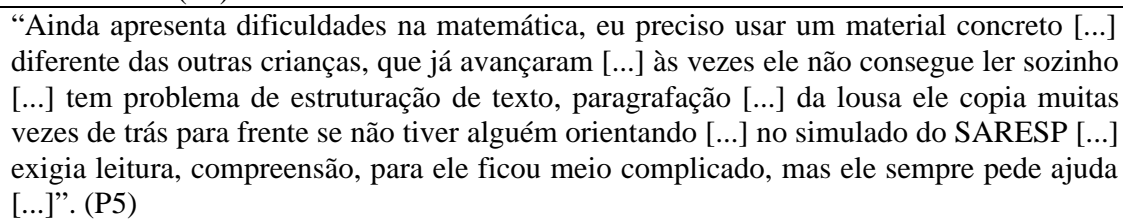 \\
\hline
\end{tabular}

Quadro 8- Dificuldade na aprendizagem.

Os participantes identificaram dificuldades dos alunos em relação à leitura, escrita, Matemática. Alguns participantes (P4 e P5) verbalizaram que os 
alunos com deficiência auditiva e mental, com quem trabal havam, apresentavam uma grande defasagem na aprendizagem em rel ação aos demais al unos.

Rossit, Araújo e Nascimento (2005) realizaram nove estudos investigando aspectos particulares das habilidades matemáticas no ensino do aluno com deficiência mental. Foi verificado que a proposta da educação matemática para pessoas com deficiência mental não está claramente definida. Os estudos revisados concentram suas investigações no conceito de número, seqüências numéricas, regras de magnitude e nas aplicações do uso do dinheiro. Os pesquisadores propõem a utilização de um currículo funcional para ensinar as habilidades matemáticas, ou seja, ensinar de maneira direta os componentes utilizados em cada uma das tarefas e, se dificuldades surgirem no decorrer do processo, desmembrar o componente específico em passos menores para que a aprendizagem possa ocorrer.

\subsection{RESUMO GERAL DAS MOdIFICAÇÕES DAS CONCEPÇÕES INICIAIS}

Ao término da análise, pode-se obter uma visão global sobre as mudanças de concepções. Pode-se observar que poucas foram a mudanças ocorridas.

Tais mudanças, como discutidas anteriormente, sereferiram à subclasse Expectativa em relação à inclusão do aluno com deficiência na sala de aula regular onde ocorreu maior número de mudanças. As mudanças de concepção nos relatos se referiram ao sentimento de medo dos professores em relação ao comportamento do aluno com deficiência, aliado ao comportamento do grupo. Porém, pôde-se perceber nos relatos das sessões seguintes, queesses sentimentos de medo deixaram de existir.

Quanto à Experiência do professor em relação à inclusão do aluno com deficiên cia, a mudança de concepção pôde ser percebida nos relatos deP2: a inserção do al uno com defi ciência não a assustava. $\mathrm{N}$ a terceira sessão, relatou que a aluna com deficiência não Ihe havia criado conflito. Já na quinta sessão de coleta, P2 relatou que lhe causou impacto afetivamente.

Sobrea Interação entreo al uno com deficiência eos al unos não deficientes na sala deaula regular, não houvemudança deconcepção. Porém, pode-seconstatar quehouve uma indicação de mudança de situação, como pode-se observar no relato deP3:

\footnotetext{
(segunda sessão) E em relação a trabalhar a aceitação com os alunos [todos os alunos]? $\mathrm{N}$ em foi necessário, eles aceitam, conversam [...] nem parece que nós estamos com a aluna incluída aqui, é normal [...].
}

Da mesma forma, o tema A daptação de atividades para o aluno com deficiência, também não houve mudança de concepção, mas mudou a situação. P3 relatou, na primeira sessão, quetinha certeza que seria necessário adaptar atividades para o al uno com deficiência. Na segunda e terceira sessão de coleta, relatou que não havia sido necessário adaptar atividades. 
Sobre o tema Perfil do aluno com deficiência para ser matriculado no ensino regular, P1 indicou um fato interessante. $\mathrm{N}$ a primeira sessão, relatou que, para ser inserido, o aluno com deficiência deveria estar preparado emocionalmente. Da terceira sessão em diante, a participante se refere ao nível cognitivo, e a exigência para a inclusão recai sobrea capacidadepara aprender, possi bilidadepara aprender, raciocinar, pensar.

Sobre o tema o ritmo de aprendizagem do al uno com deficiência, foi possível também perceber mudança de concepção no relato de P2, segunda sessão de coleta: “[...] [aluna com deficiência] está realizando as tarefas, nem parece uma aluna especial [...]". Por esse relato, transparece a crença de que alunos com deficiência, muito provavelmente, não tenham condições de acompanhar o mesmo ritmo de aprendizagem quealunos sem deficiência. N a sexta sessão de coleta, última etapa, a participante relatou:

"A aluna deficiente está melhor que os alunos que renderam o mínimo deles, ela conseguiu ficar com a média mel hor que muitas crianças que nunca tiveram problema, eu acho que ela superou até as expectativas dela".

No tema M etodologia de trabalho voltada para a inclusão do aluno com deficiência na sala de aula regular, P3 relatou, na primeira sessão, que acreditava ser necessário utilizar uma metodologia diferente para trabalhar com alunos com deficiência na sala de aula regular. Na terceira sessão de coleta, afirmou que não foi preciso mudar a metodologia.

Sobre o tema avaliação, P3 relatou inicialmente que seria necessário realizar uma aval iação diferente com o aluno com deficiência, posteriormente, na terceira sessão de coleta, relatou quea aluna com deficiência fez a mesma avaliação que os colegas.

N este mesmo tema, P5, primeiramente, indicou que havia diferenciado a avaliação apenas para o al uno com deficiênciae, na sessão seguinte, relatou: “Foi diferenciada, não só para ele [aluno com deficiência] para os outros al unos a gente teve que ter outro ol har sobre o próprio progresso dos alunos [...]".

Em relação ao tema $D$ ificuldade em lidar com a diversidade em sala de aula, a mudança de concepção foi percebida nos relatos de P4. Em seu relato inicial, foi possível perceber a crença de que alunos surdos sempre apresentam problemas relacionados à comunicação e, portanto, sempre haveria uma barreira para o ensino, já na sessão seguinte, a participante relatou: “[...] el e fala e eu entendo o que ele fala, então não é tão complexo [...]".

Nos relatos deP5, sobre adificuldade do professor para ensinar o aluno com deficiência, pôde-se perceber quea crença inicial era a dequeseria muito complicado ensiná-los. Posteriormente, a participante pareceu ter mudado sua concepção em relação a essa questão: “Para ensinar não está tão complicado como eu imaginava que seria um pouco mais". 
$\mathrm{N}$ a subclasse $\mathrm{D}$ ificuldade em lidar com a disciplina/comportamento do al uno com deficiência em sala de aula, nos relatos de P2 eP3, pôde-se perceber mudança de concepção. P3 indicou surpresa com o fato de a aluna com deficiência não apresentava problemas de comportamento: “[...] nem parece que ela éuma aluna incluída [...] eu estava com medo da disciplina [...] mas com esta aluna, não está tendo problema. Isto também foi uma surpresa [...]". P2 relatou, na segunda sessão: "[...] mas, por enquanto, está dando para levar como seela não tivessesido incluída" e na sexta sessão relatou:

[...] ela não teve problemas mesmo. Eu ouço falar de outros alunos incluídos que é na disciplina que eles às vezes dão algumas alterações, mas como nós temos também alunos brilhantes que dão problemas terríveis de disciplina, eu não acho que isso seja uma característica só do deficiente, tem que ter um jogo de cintura muito grande do professor.

N os relatos da maioria dos participantes, o quese pôde notar, foi queo grande medo, com relação à inclusão, estava mais relacionado a questões ligadas ao comportamento edisciplina do aluno. A maioria dos participantes indicou que o grande número de alunos na sala de aula regular, dificulta o atendimento dos alunos, no geral, e, relataram ainda, sobre a necessidade de preparação do professor para a inclusão.

\section{CONCLUSÃO}

As mudanças deconcepções ocorridas foram poucas; al gumas serviram para modificar as crenças, mas as concepções sobre aprendizagem não foram tocadas, pois todos os participantes indicaram que seus alunos apresentavam al guma dificuldadena aprendizagem. Os participantes apresentaram maior número de mudanças de concepções na subclasse Expectativa em rel ação à inclu são do al uno com deficiência na sala de aula regular, sendo que os relatos de P3 foram os que apresentaram mais mudanças.

Os relatos, de forma geral, parecem demonstrar, o que se poderia chamar de profecia auto-cumpridora, os relatos dos participantes partem de um preconceito (pré-conceito) que pode se realizar.

Como já citado anteriormente, alguns estudos da literatura apresentaram mudanças de concepções em rel ação à inclusão (GAM BA RO, 2002; PEREIRA, 2002; ORTIZ, 2003; ROSA, 2003; ADAMUZ; 2003). Porém, essas mudanças deconcepções observadas ocorreram após trabal hos deintervenção com professores, incluindo cursos de capacitação, programas detreinamento, reuniões para orientação e acompanhamento do professor.

As ações direcionadas para a inclusão do aluno com deficiência no ensino regular, como por exemplo, a oferta de cursos de capacitação, diminuição do número de alunos por sala de aula regular, trabal ho em conjunto do professor especial izado/ professor do ensino regular, entre outras, poderiam contribuir para que, gradativamente, fosse implementada a inclusão. 
Os relatos dos participantes demonstraram que, por si só, o simples ingresso dos al unos em sala não foi suficiente para que ocorressem mudanças de concepções, fato que precisa ser consi derado nos processos de inclusão escolar.

\section{REFERÊNCIAS}

ADAMUZ, R. C. Inserção de um al uno deficienteem cl asse comum: uma refl exão sobrea prática pedagógica. Londrina: A trito Art Editorial, 2003.

BARDIN, L. A nálise de Conteúdo. Tradução de Luís A ntero Reto eA Augusto Pinheiro. Lisboa: Edições 70, 2000.

BAUER, M. W.; GASKELL, G. Pesquisa qual itativa com texto, imagem esom: um manual prático. Tradução dePedrinho A. Guareschi. 3. ed. Petrópolis: Vozes, 2004.

BLAN CO, R; DUCK, C. A integração dos al unos com necessidades especiais na região da A mérica Latina e Caribe: situação atual e perspectivas. In: MANTOAN, M.T. E. A integração depessoas com deficiência: contribuições para uma reflexão sobreo tema. São Paulo: Memnon Editora SEN AC, 1997. p. 184-195.

BRASIL, Ministério da Educação e do Desporto. Secretaria de Educação Fundamental. Referencial Curricular N acional para a E ducação Infantil. Brasília: MEC/ SEF, 1998, v. 1.

DAL-FORNO, J. P.; OLIVEIRA, V. F. Ultrapassando barreiras: professoras diante da inclusão. Disponível em: বhttp:/ / www.ufsm.br/ ce/ revista/ ceesp/ 2005/ 02/ a10.htm>. Acesso em: 21 dez. 2005.

DIAS, T. R. S.; OM OTE, S. Entrevista em Educação Especial: aspectos metodológicos. R evista brasileira de educação especial, Marília, v. 3, p. 93-100, 1995.

FAGUNDES, A. J. F. M. D escrição, definição e registro do comportamento. 12. ed. São Paulo: EDICON,1999.126p.

FUJISA WA, D. S. U tilização de jogos ebrincadeiras como recurso no atendimento fisi oterapêutico de crianças: implicações na formação do fisioterapeuta, 2000. 143 f. Dissertação (M estrado em Educação)- FaculdadedeFilosofia eCiências, UniversidadeEstadual Paulista, Marília, 2000.

GAMBARO, J. C. Capacitação de professores de classe inclusiva: efeitos sobre as atividades frente ao aluno com deficiência auditiva, 2002. 138f. Dissertação (M estrado em Educação Especial ) - Universidade Federal de São Carlos, São Carlos, 2002.

JANIAL, M. I.; MANZINI, E. J. Integração de al unos deficientes sob o ponto de vista do diretor de escola. In: MANZINI, E. J. (Org). Integração do al uno com deficiência: perspectiva e prática pedagógica. Marília: UN ESP-Marília-Publicações, 1999. p. 1-25.

MANZINI, E. J. A entrevista na pesquisa social. In: Didática: São Paulo, v. 26/ 27, p. 149158. 1990/ 1991.

MANZINI, E. J.; SIMÃO, L. M. Concepção do professor especializado sobre a criança deficientefísica: mudanças em alunos em formação profissional. In: DIAS, T. R. S.; DENARI, F. E.; KUBO, O. M . (Org). T emas em E ducação Especial 2. São Carlos: UFSCar, 1993. p. 25-54. MANZINI, E. J. Entrevista semi-estruturada: análise de objetivos e de roteiros. In: SEMINÁRIO INTERNACIONAL DE PESQUISA E ESTUDOS QUALITATIVOS, 2, A pesquisa qualitativa em debate. A nais... Bauru: SIPEQ, 2004. 1 CD.

MELO, F. R. L. V.; MARTINS, L. A. R. O quepensa a comunidadeescolar sobreo al uno com paralisia cerebral. Revista Brasileira de E ducação Especial, Marília, v. 10, n. 1, p. 75-92, 2004. 
MENDES, E. G. D eficiência mental: a construção científica de um conceito e a realidade educacional, 1995. $387 \mathrm{f}$. Tese (Doutorado em Psicologia)- Instituto de Psicologia, Universidade de São Paulo, São Paulo, 1995.

. Reconstruindo a concepção de deficiência na formação de recursos humanos em Educação Especial. In: MARQUEZINI, M. C.; ALMEIDA, M. A.; TANAKA, E. D. O. (Org). Perspectivas multidisciplinares em educação especial II. Londrina: Ed. UEL, 2001. p. 53-64.

MONTEIRO, A.P. H. H á mudanças nas con cepções do professor do ensino fundamental em relação à inclusão após a inserção deal unos deficientes? 2006. 140f. Dissertação (M estrado em Educação) - Universidade Estadual Paulista "Júlio de Mesquita Filho", Faculdade de Filosofia e Ciências, Marília, 2006.

ORTIZ, L. G. M. Capacitando professores de ensino fundamental em serviço para uma educação Inclusiva, 2003. 125f. Dissertação (M estrado em Educação Especial) - Universidade Federal de São Carlos, São Carlos, 2003.

PEREIRA, E. C. A valiação de uma experiência de formação para formadores de professores de magistério sobre edu cação inclusiva, 2002. 97f. Dissertação (M estrado em Educação Especial) - Universidade Federal de São Carlos, São Carlos, 2002.

QUEIROZ, M. I. P. V ariações sobre a técnica de gravador no registro da informação viva. São Paulo: T. A. Queiroz, 1991, v. 7.

ROSA, L. C. S. Formação con tinuada de seus atendentes para inclu são de crianças com necessidades educacionais especiais em creches, 2003. 156f. Dissertação (M estrado em Educação Especial) UniversidadeFederal de São Carlos, São Carlos, 2003.

ROSSIT, R. A. S.; ARAUJO, P. M.; NASCIMENTO, M. H. Matemática para deficientes mentais como objeto de pesquisa: análise e perspectivas. Revista Brasileira deE ducação Especial, Marília, v. 11, n. 1, p. 119-142, 2005.

SAAD, S. N. Preparando o caminho dainclusão: dissolvendo mitos epreconceitos em relação à pessoa com Síndrome de Down. Revista Brasileira de Educação Especial, Marília, v. 9, n. 1, p. 57-58, 2003.

SILVA, A. B. P.; PEREIRA, M. C. C. O al uno surdo na escola regular: imagem e ação do professor. Disponível em: $\measuredangle$ ttp:/ / www.scielo.br/ scielo.php?script=sci_2002>. A cesso em: 20 dez. 2005.

TESSA RO, N. S. Inclusão escol ar: concepções de professores ealunos da educação regular e especial. São Paulo: Casa do Psicólogo, 2005.

TUNES, E.; SIMÃ O, L. M. Sobreanálise do relato verbal. Psicologia U SP , São Paulo, v. 9, n. 1, p. 303-324, 1998.

VALLE, M. H. F.; GUEDES, T. R. H abilidades do professor frenteà inclusão. In: SOBRIN HO, F. P. N. (Org). Inclusão educacional: pesquisa e interfaces. Rio de Janei ro: Livre Expressão, 2003, p. 42-61.

VITALIANO, C. R. Concepção de professores universitários da área de E ducação e do ensino regular sobre o processo de integração de alunos especiais e a formação de professores, 2002. $308 \mathrm{f}$. Tese (Doutorado em Educação)- Faculdade de filosofia e Ciências, Universidade Estadual Paulista, Marília, 2002.

Recebido em 18/ 05/ 2007

Reformulado em 26/ 07/ 2007

A provado em 29/ 10/ 2007 